\title{
Xerogels of ammonium polyvanadatomolybdate as starting material for ammonia gas sensors
}

\author{
V. Bondarenka ${ }^{1,2}$, R. Sereika ${ }^{2}$, A. Mironas ${ }^{1}$, S. Grebinskij ${ }^{1}$ \\ ${ }^{1}$ Semiconductor Physics Institute, Center for Physical Sciences and Technology, \\ A. Goštauto 11, LT-01108 Vilnius, Lithuania \\ ${ }^{2}$ Faculty of Science and Technology, Lithuanian University of Educational Sciences, \\ Studentu 39, LT-08106 Vilnius, Lithuania \\ E-mail address: raimundas.sereika@leu.It
}

\section{INTRODUCTION}

The various gas sensors were designed for detection of different gases in the air using different oxides and impurities [1-3]. For example the manufacturing of ammonia sensors on the basis of $\mathrm{Cu}_{\mathrm{x}} \mathrm{S}$-micro-porous-Si structure includes manufacture of micro-porous silicon, drawing on it of $\mathrm{SiO}_{2}$ isolating layer, and then the $\mathrm{Cu}_{\mathrm{x}} \mathrm{S}$ layer $[4,5]$. The special equipment for all these processes is needed. More usable method for sensor production is so-called soft chemistry or solgel synthesis $[6,7]$.

Sol-gel process can be used to produce a wide range of various compounds (usually oxides) including their thin films, nanopowders, fibers, glasses, ceramics, organic-inorganic hybrids, and so on. The sol-gel process can be characterized by a series of discrete steps. Step 1: formation of the "sol" i.e. colloidal suspension of solid particles (usually salts of necessary materials) in a liquid (solvent for necessary materials). Step 2: gelation resulting from the formation of an oxide network (the gel) by a polycondensation that results in a dramatic increase in the viscosity of the solution. This network structure may result from physical or chemical bonds, as well as crystallites or other junctions that remain intact within the extending fluid. Step 3: formation of a xerogel - a solid formed from a gel by drying usually in air atmosphere. As a result all solvent components that are not bonded with oxide network abandon the gel. A lot of various vanadium hydrated compounds were synthesized by using this simple method [8]. The sol-gel technology is also widely used for the production of the humidity sensors based on the vanadium hydrated compounds $[9,10]$.

The chemical composition of produced materials was investigated using the X-ray photoelectron spectroscopy (XPS) method. XPS is known as the surface analysis method which provides the direct information on the species concentration and their valence states. So we use these features of the method for studies of the surface composition of investigated xerogels.

In the present paper, we introduce the ammonia gas sensor based on the vanadiummolybdenum-ammonium oxide hydrate that could operate at the room temperature area.

\section{Experimental}

The ammonium polyvanadatomolybdate xerogels were synthesized using $\mathrm{V}_{2} \mathrm{O}_{5}, \mathrm{NH}_{4} \mathrm{VO}_{3}$, $40 \% \mathrm{H}_{2} \mathrm{O}_{2}$, and Mo powder. $\mathrm{V}_{2} \mathrm{O}_{5}$, Mo powders and $\mathrm{NH}_{4} \mathrm{VO}_{3}$ in a suitable proportion were dissolved in $\mathrm{H}_{2} \mathrm{O}_{2}$ to form mixed solutions of pervanadic (molybdic) acids. Slow heating up to 333 $\mathrm{K}$ initiates the decomposition of the peroxide compounds, followed by gelation. The reactions with the participation of $\mathrm{V}_{2} \mathrm{O}_{5}$ are following:

$$
\begin{aligned}
& \mathrm{V}_{2} \mathrm{O}_{5}+2 \mathrm{H}_{2} \mathrm{O}_{2}=2 \mathrm{HVO}_{2}\left(\mathrm{O}_{2}\right)+\mathrm{H}_{2} \mathrm{O}, \\
& \mathrm{HVO}_{2}\left(\mathrm{O}_{2}\right)+3 \mathrm{H}_{2} \mathrm{O}=\mathrm{VO}(\mathrm{OH})_{3}\left(\mathrm{OH}_{2}\right)_{2}+\frac{1}{2} \mathrm{O}_{2}, \\
& 2\left[\mathrm{VO}(\mathrm{OH})_{3}\left(\mathrm{OH}_{2}\right)_{2}\right] \rightarrow \mathrm{V}_{2} \mathrm{O}_{5} \cdot 5 \mathrm{H}_{2} \mathrm{O} .
\end{aligned}
$$


The reaction (3) represents polymerization of the neutral precursor, resulting in a hydrous $\mathrm{V}_{2} \mathrm{O}_{5}$ gel, which can be regarded as the polyvanadic acid $\mathrm{H}_{2} \mathrm{~V}_{12} \mathrm{O}_{31 \pm \delta} \cdot n \mathrm{H}_{2} \mathrm{O}$. Decomposition of the peroxide solution of vanadium containing only $\mathrm{NH}_{4}{ }^{+}$ions is not accompanied by gelation, whereas, in the presence of molybdenum, $\left(\mathrm{NH}_{4}\right) \mathrm{HV}_{9} \mathrm{Mo}_{3} \mathrm{O}_{31 \pm \delta} \cdot n \mathrm{H}_{2} \mathrm{O}$ gels are formed [11]. Obtained gels were deposited on $\mathrm{Ni}$ substrates by screen printing method and dried in air. The thickness of prepared films was about $10 \mu \mathrm{m}$. The films have layered structure where $\mathrm{NH}^{4+}$ ions and $\mathrm{H}_{2} \mathrm{O}$ are incorporated between the V-O-Mo layers [10]. Such structure causes anisotropy of physical properties of the produced films along and across the V-O-Mo layers that is peculiar to the other hydrated vanadium compounds [11].

Surface chemical composition was inspected using the XPS method. XSAM 800 (Kratos Analytical, UK) was used to record the X-ray photoelectron spectra. A nonmonochromatized $\mathrm{Mg}$ $\mathrm{K}_{1,2} \quad(1253.6 \mathrm{eV})$ radiation source excited the photoelectrons at $15 \mathrm{kV}, 300 \mathrm{~W}$. During the spectrum analysis the working pressure was below $10^{-7} \mathrm{~Pa}$ in the analysis chamber. The analyzer used with an energy resolution $\Delta E / E=0.08 \%$ in steady retarding mode. Using KRATOS DS800 data system the photoemission data has been collected and processed. The multiple photoelectron spectra were separated into several peaks setting the peak position: binding energy (BE), area (A), width (FWHM), and Gaussian/Lorentzian $(\mathrm{G} / \mathrm{L})$ ratio. The accuracy of the relative intensities and $\mathrm{BE}$ of the measured lines were about $10 \%$ and $0.1 \mathrm{eV}$ respectively. The random $\mathrm{C} 1 \mathrm{~s}$ line the $\mathrm{BE}$ of which should have been equal to $284.6 \mathrm{eV}$ was used for the correction of the charging effects. After the $\mathrm{Mg} \mathrm{K} \mathrm{K}_{\alpha 1,2}$ source satellites and Shirley background [12] subtraction, a non-linear least squares curve fitting routine with a Gaussian/Lorentzian product function was used for the analysis of XPS spectra. Before the measurements the surface of samples was cleaned using $\mathrm{Ar}^{+}$ions bombardment at $3 \mathrm{kV}$ and current density of $10 \mu \mathrm{A} \cdot \mathrm{cm}^{-2}$ for $3 \mathrm{~min}$. The energy scale was calibrated using the Au 4 $\mathrm{f}_{7 / 2}$ peak $(84.0 \mathrm{eV})$.

Electrical contacts of the sensitive films were manufactured by a dc-magnetron sputtering in Ar atmosphere from a metallic In target. The contacts were deposited in two configurations as shown in Fig. 1. These configurations of the contacts allow to investigate physical properties of the films across (a) and along (b) V - O - Mo layers.

DC-electrical resistance was measured for the samples in clean air and air contaminated with the target gas (ammonia). For this, the sensors were situated in a test chamber with ambient air. The chamber was equipped with special inlets for injection of the target gas and for purging the gas out with clean air. The resistance of the films was calculated by measuring output voltage on the resistance connected in series with the sample as a time function during the tests.

\section{Results and Discussion}

The successful synthesis of the $\left(\mathrm{NH}_{4}\right) \mathrm{HV}_{9} \mathrm{Mo}_{3} \mathrm{O}_{31 \pm \delta} \cdot n \mathrm{H}_{2} \mathrm{O}$ xerogel was confirmed using XPS spectra study where presence of $\mathrm{NH}_{4}^{+}, \mathrm{Mo}^{6+}, \mathrm{V}^{4+}, \mathrm{V}^{5+}$ ions, oxygen ions $\mathrm{O}^{2-}$ connected with molybdenum and vanadium ions, and oxygen in water molecules were captured. Figure 2 shows the XPS spectrum of $\left(\mathrm{NH}_{4}\right) \mathrm{HV}_{9} \mathrm{Mo}_{3} \mathrm{O}_{31 \pm \delta} \cdot \mathrm{nH}_{2} \mathrm{O}$ xerogel in the vanadium - oxygen region (points are experimental data). V $2 p$ and $\mathrm{O} 1 \mathrm{~s}$ peaks are composed of several components. V $2 \mathrm{p}_{3 / 2}$ and $\mathrm{V} 2 \mathrm{p}_{1 / 2}$ peaks consists of two components and $\mathrm{O}$ 1s peak consists of three components. It is possible to subsume that the $\mathrm{V} \mathrm{2} \mathrm{p}_{3 / 2}$ peak components with binding energies $516.03 \mathrm{eV}$ and $517.53 \mathrm{eV}$ corresponds to the quadrivalent [13] and quinquivalent [14] vanadium ions in the xerogel, respectively. The same can be said about the $\mathrm{V} 2 \mathrm{p}_{1 / 2}$ peak components with binding energies of $523.5 \mathrm{eV}$ and $524.98 \mathrm{eV}$ [15]. From V 2 $p_{3 / 2}$ peak components' areas one can calculate the vanadium ions reduction ratio $\mathrm{C}=\mathrm{C}_{\mathrm{V} 4+} /\left(\mathrm{C}_{\mathrm{V} 5+}+\mathrm{C}_{\mathrm{V} 4+}\right)$ where $\mathrm{C}_{\mathrm{V} 5+}$ and $\mathrm{C}_{\mathrm{V} 4+}$ are the concentrations of the corresponding ions. In our case $C=0.043$, i. e. quadrivalent vanadium constitutes just $4.3 \%$ of vanadium ions content similar as in other vanadium hydrates [8]. The $\mathrm{O}$ 1s peak has three components (see Fig. 2). The first one, a more intensive component, with binding energy $530.48 \mathrm{eV}$ matches the $\mathrm{O}^{2-}$ ions [16] linked with vanadium and molybdenum ions. The second one, less intense $(531.4 \mathrm{eV})$, is possible to assign to the relations with carbon [16]. And the last and weakest component with binding energy at $533.01 \mathrm{eV}$ matches the oxygen linked with hydrogen in water 
molecules [17]. In Fig. 3 the XPS spectrum of molybdenum (Mo 3 $p_{3 / 2}$ ) and nitrogen region is shown. The fact that Mo $3 \mathrm{p}_{3 / 2}$ and $\mathrm{N} 1 \mathrm{~s}$ binding energies are close to each other makes the analysis of this spectrum more complex, whereas the neglect of nitrogen presence in the gel makes the interpretation of this spectrum quite difficult. The component with binding energy $398.68 \mathrm{eV}$ matches $\mathrm{Mo}^{6+}$ ions [18] and the component with binding energy $401.76 \mathrm{eV}$ matches nitrogen which is in $\mathrm{NH}_{4}{ }^{+}$ions [19]. Mo $3 \mathrm{~d}$ emission comprises the pair of spin - orbit doublets with Mo $3 \mathrm{~d}_{3 / 2}$ and Mo $3 \mathrm{~d}_{5 / 2}$ binding energies of $\sim 236 \mathrm{eV}$ and $\sim 233 \mathrm{eV}$ respectively that was observed in other vanadium hydrates containing molybdenum [20].

$\left(\mathrm{NH}_{4}\right) \mathrm{HV}_{9} \mathrm{Mo}_{3} \mathrm{O}_{31 \pm \delta} \cdot \mathrm{nH}_{2} \mathrm{O}$ xerogel was tested as a possible material for ammonia gas sensor. Fig. 4 shows the resistance response to ammonia gas injection ("In" on Fig. 4) and removal (“Off"on Fig. 4) versus time measured across (contacts configuration - Fig. 1b) V - O - Mo layers. In this case the resistance response of the sample increases after ammonia injection then decreases and practically does not change with time even after removing the gas from the chamber ("Off'on Fig. 4). It is clear that "across" configuration of the samples contacts is unusable for the gas sensors production. Figure 5 shows the resistance response to ammonia gas injection ("In" on Fig. 5) and removal ("Off "on Fig. 5) versus time measured along (contacts configuration - Fig.1a) V - O Mo layers. In this case after gas injection the resistance response at first three seconds increase, then practically do not changes about 5-6 seconds (region A on Fig. 5), then decrease and after that do not changes with time (region B on Fig. 5). After gas removal from the testing chamber the resistance response increase and then do not depends on the time. So, by measuring the resistance response in regions $\mathrm{A}$ and $\mathrm{B}$ (Fig. 5) we can determine the ammonia gas presence in the testing chamber. Figure 6 presents the resistance response dependence on gas concentration measured in region A. The experimental results (points in Fig. 6) can be described as linear function

$$
\frac{R}{R_{0}}=\alpha+\beta \cdot \mathrm{NH}_{3},
$$

where $\alpha$ and $\beta$ are some constants and $\mathrm{NH}_{3}$ - the concentration of ammonia gas in chamber. Solid line in Fig. 6 presents the calculation results using (5) and $\alpha=1.01253 \pm 0.01418, \beta=(0.02337 \pm$ $0.00141) \%^{-1}$. The value of constant $\beta$ specifies the sensitivity of the xerogel to ammonia gas concentration.

The resistance response dependence on gas concentration measured in region B is shown on Fig. 7. The experimental results (points on Fig. 7) can be described as exponential function

$$
\frac{R}{R_{0}}=\left(\frac{R}{R_{0}}\right)_{0}+C \cdot \exp \left(\left(-N H_{3}\right) \cdot t\right)
$$

where $\mathrm{NH}_{3}$ - the concentration of ammonia gas, $\left(R / R_{0}\right)_{0}=0.7731 \pm 0.01509, \mathrm{C}=0.2286 \pm 0.02521$, and $t=(0.348 \pm 0.0949) \%^{-1}$ (calculation results are shown on Fig. 7 - solid line). In this case the resistance response exponentially decreases with gas concentration and practically does not changes at the large values of the ammonia concentration. So, this concentration measurement method in region B in Fig. 7 is not usable.

\section{Conclusions}

The ammonium polyvanadatomolybdate $\left(\mathrm{NH}_{4}\right) \mathrm{HV}_{9} \mathrm{Mo}_{3} \mathrm{O}_{31 \pm \delta} \cdot n \mathrm{H}_{2} \mathrm{O}$ xerogels were synthesized from $\mathrm{V}_{2} \mathrm{O}_{5}, \mathrm{NH}_{4} \mathrm{VO}_{3}, 40 \% \mathrm{H}_{2} \mathrm{O}_{2}$, and Mo substances using sol-gel technology method. Heating up to $333 \mathrm{~K}$ mixed solutions of pervanadic (molybdic) acids and $\mathrm{NH}_{4} \mathrm{VO}_{3} \mathrm{~K}$ initiates the decomposition of the peroxide compounds. Decomposition of the peroxide solution of vanadium containing only $\mathrm{NH}_{4}^{+}$ions is not accompanied by gelation, whereas, in the presence of molybdenum, $\left(\mathrm{NH}_{4}\right) \mathrm{HV}_{9} \mathrm{Mo}_{3} \mathrm{O}_{31 \pm \delta} \cdot n \mathrm{H}_{2} \mathrm{O}$ gels are formed. Obtained xerogels have layered structure where among the $\mathrm{V}-\mathrm{O}-$ Mo layers $\mathrm{NH}_{4}{ }^{+}$ions and $\mathrm{H}_{2} \mathrm{O}$ are incorporated. 
The resistance response versus ammonia concentration after ammonia injection in the testing camera was studied for two samples configurations - planar, when resistance response was measured along V - Mo - O layers and sandwich - across layers. It was shown that "across" configuration of the samples contacts is unusable for the gas sensors production because the resistance response of the sample practically does not change with time even after removing the gas from the testing chamber. More usable is planar sample configuration when resistance response versus ammonia concentration was measured along $\mathrm{V}-\mathrm{Mo}-\mathrm{O}$ layers. In this case, after gas injection, the resistance response at first increased, then practically do not change about $5-6$ seconds, later decreased and after that did not change with time. After gas removal from the testing chamber the resistance response increased and later did not change on time. The resistance response after gas injection can be described by the linear function $\left(R / R_{0}\right)=\alpha+\beta \cdot \mathrm{NH}_{3}$ where $\alpha=1.01253 \pm$ $0.01418, \beta=(0.02337 \pm 0.00141) \%$, and $\mathrm{NH}_{3}$ is the concentration of ammonia gas in the chamber. The value of constant $\beta$ specifies the sensitivity of the xerogel to ammonia gas concentration.

\section{Acknowledgements}

R. Sereika acknowledges European Union Structural Funds project "Postdoctoral Fellowship Implementation in Lithuania" for funding his postdoctoral fellowship.

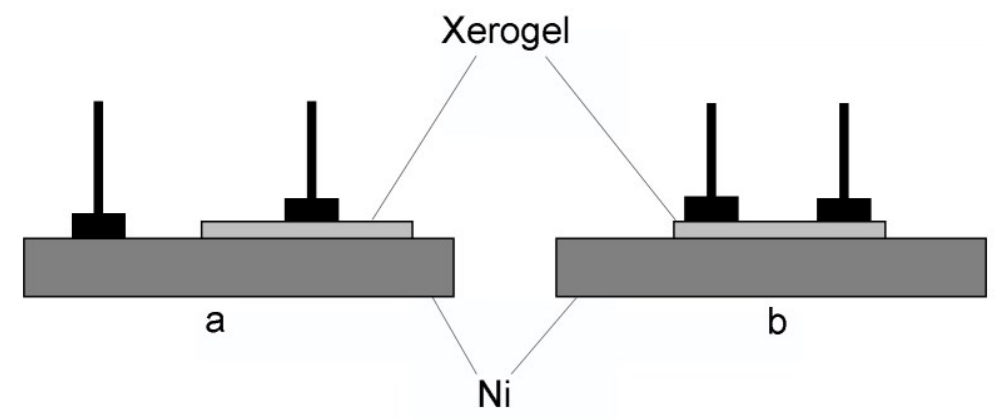

Fig. 1. Configuration of electrodes for resistance measurements across (a) and along (b) $\mathrm{V}-\mathrm{O}-$ Mo layers. 


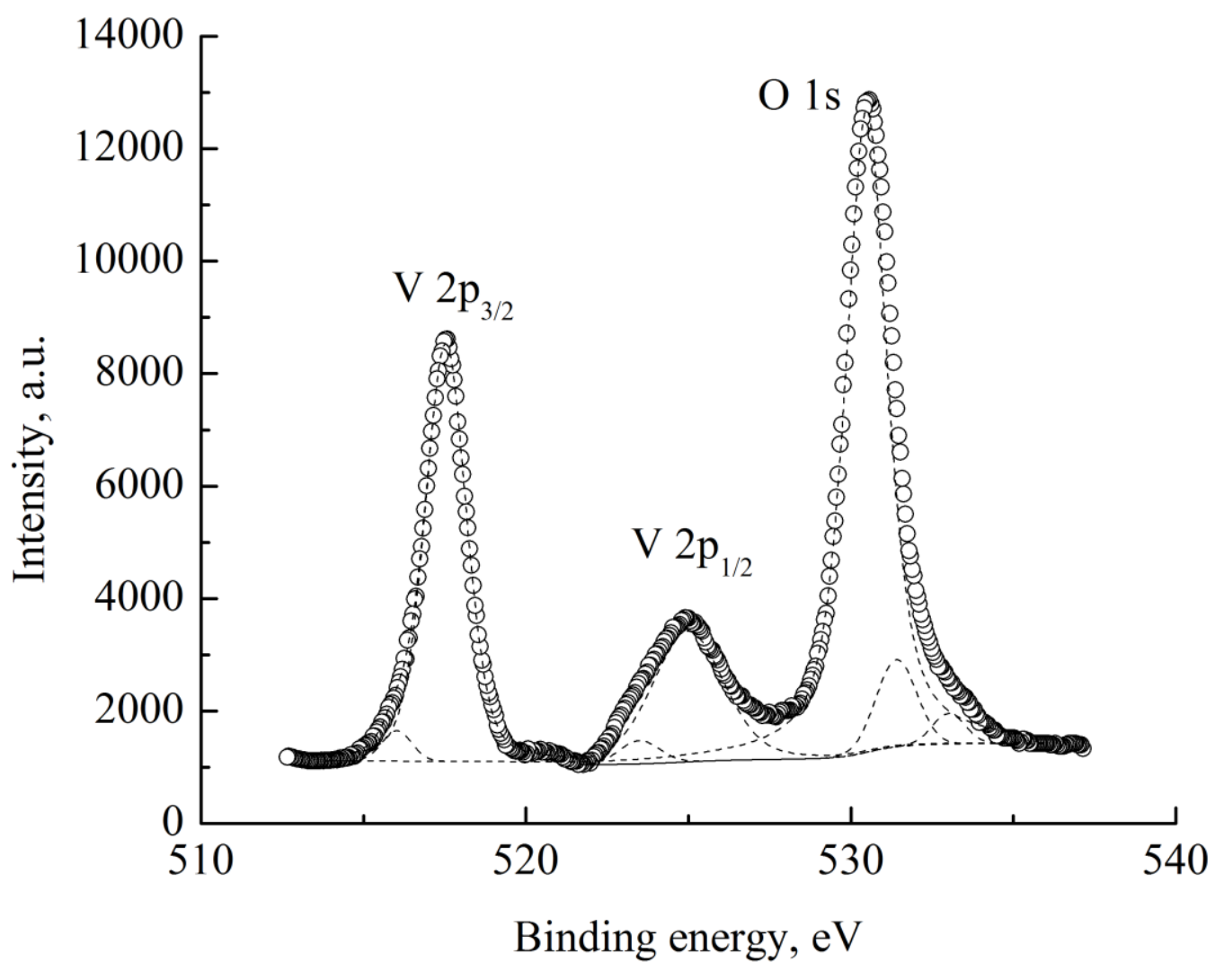

Fig. 2. XPS $\mathrm{V}-\mathrm{O}$ region spectra of $\left(\mathrm{NH}_{4}\right) \mathrm{HV}_{9} \mathrm{Mo}_{3} \mathrm{O}_{31 \pm \delta} \cdot n \mathrm{H}_{2} \mathrm{O}$ xerogel. 


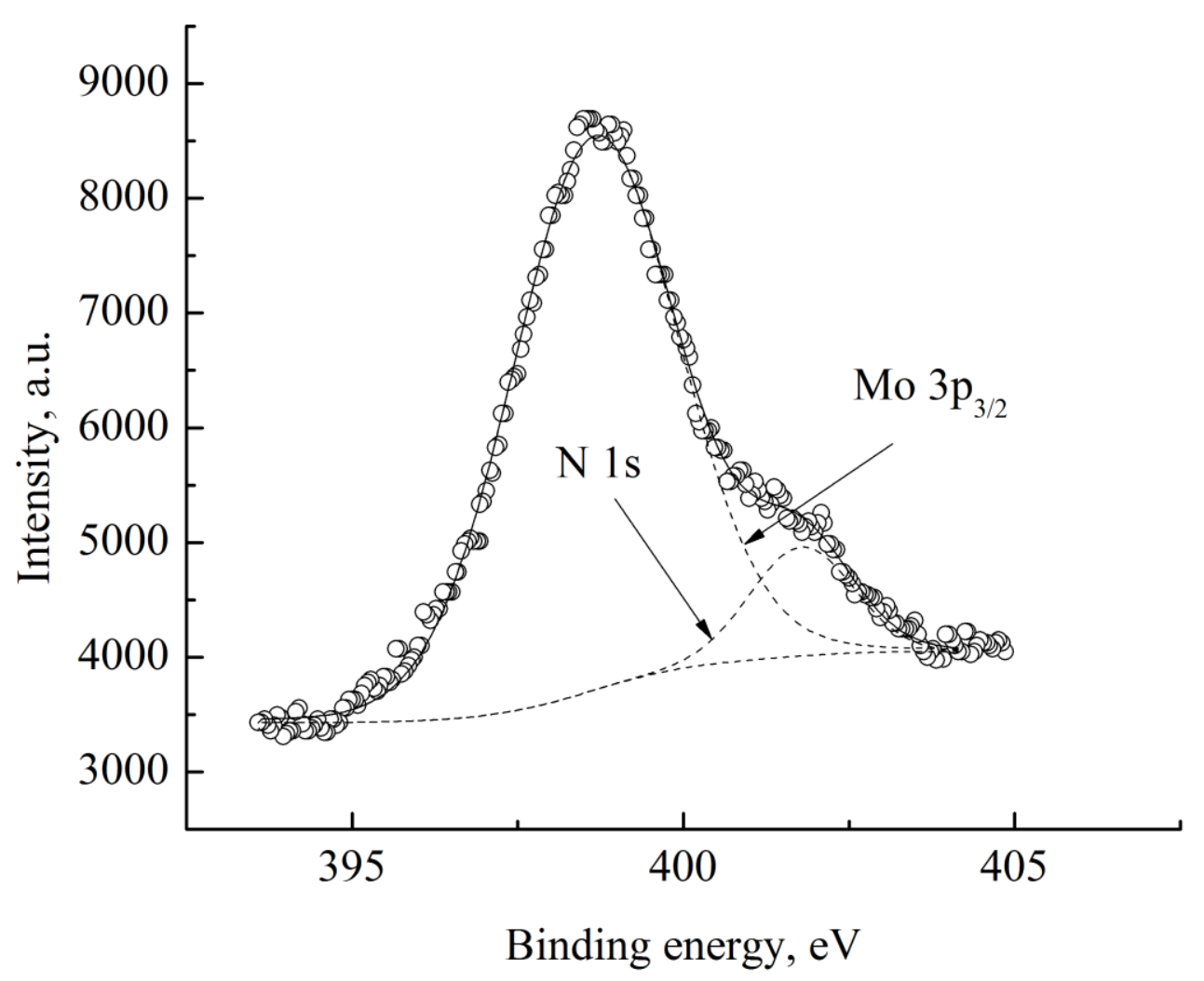

Fig. 3. XPS spectra of molybdenum (Mo 3p) and nitrogen (N 1s) region.

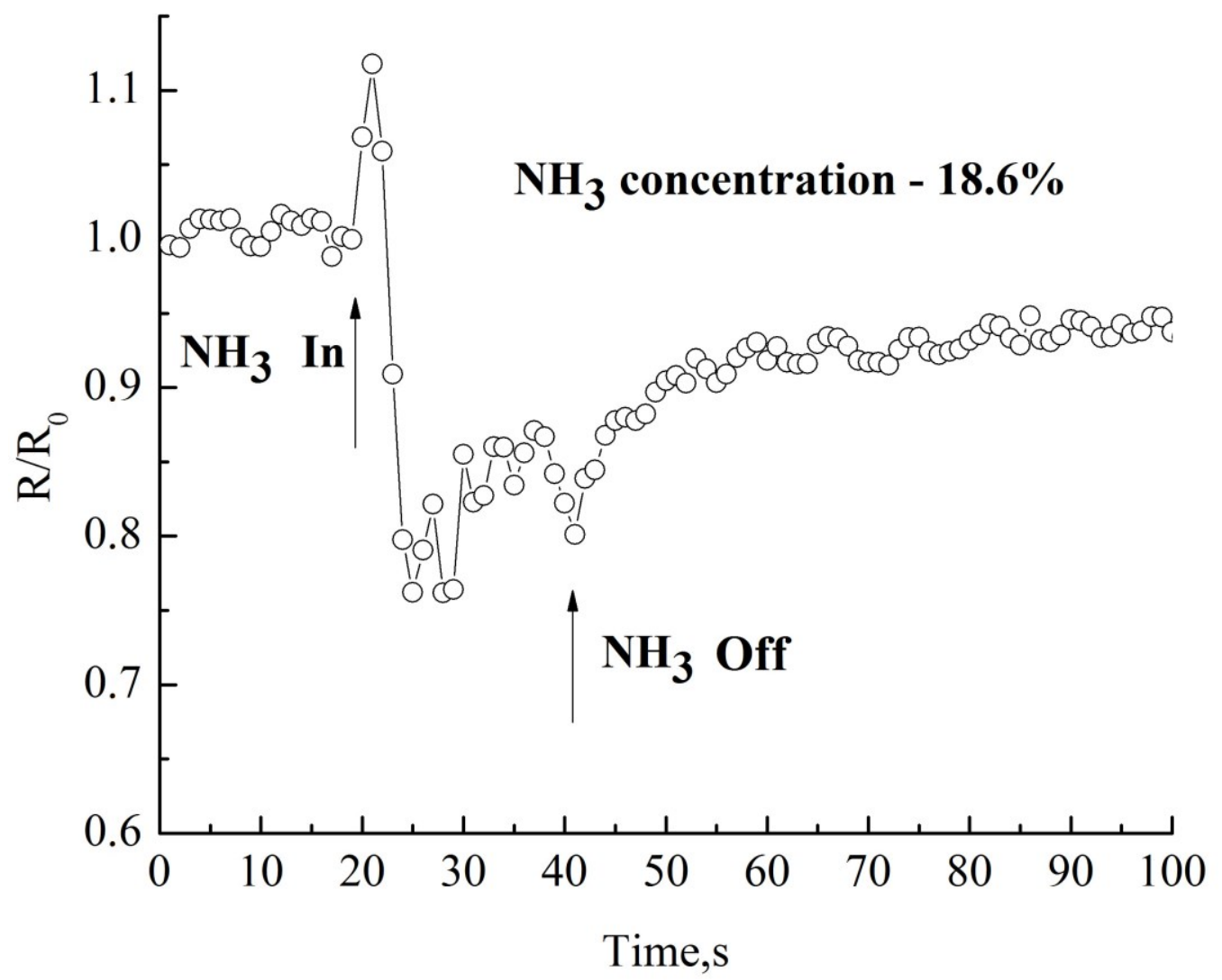

Fig. 4. The time dependence of the resistance response to ammonia measured across (contacts configuration - Fig.1b) V - O - Mo layers. 


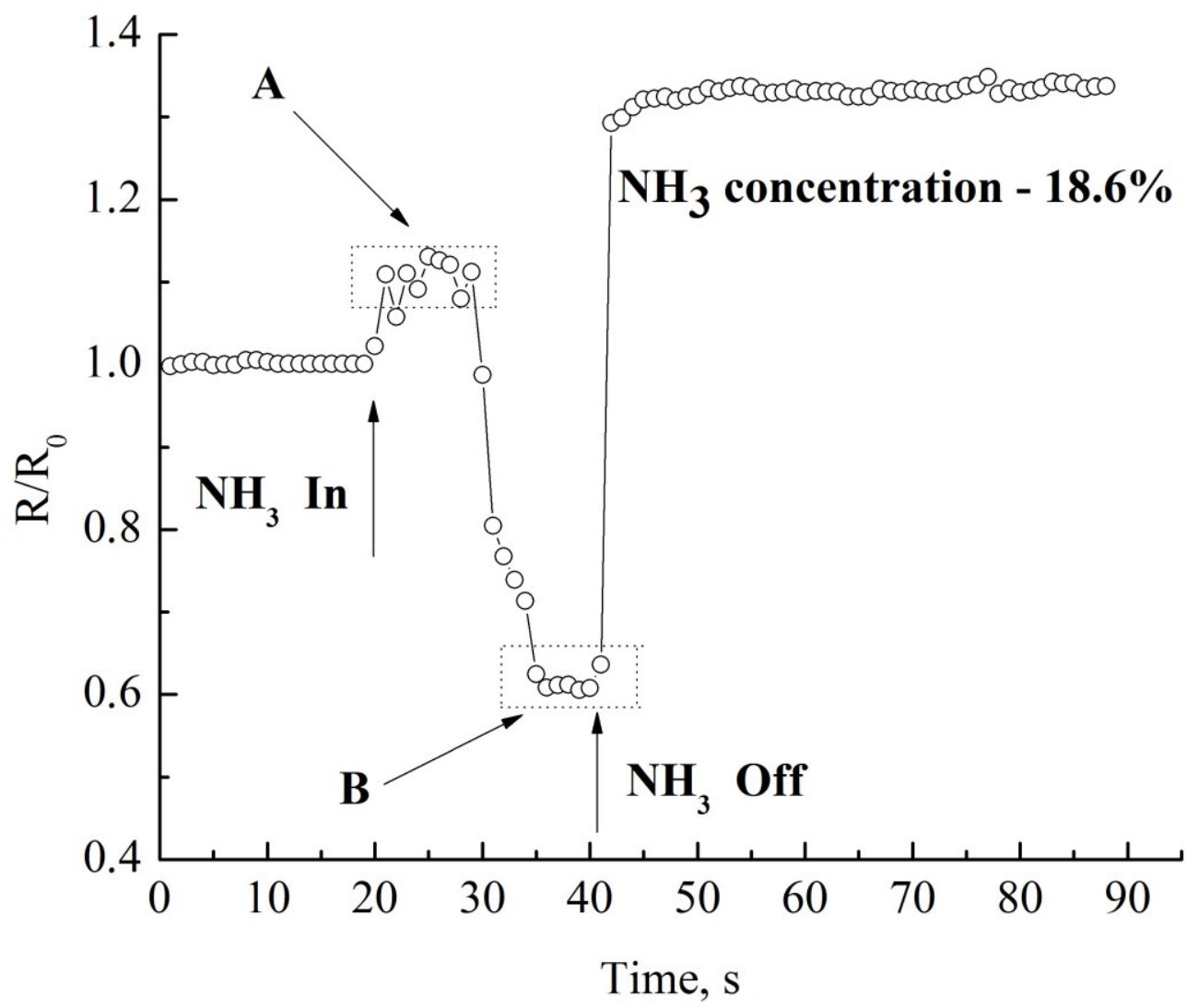

Fig. 5. The time dependence of the resistance response to ammonia measured along (contacts configuration Fig.1a) V - O - Mo layers.

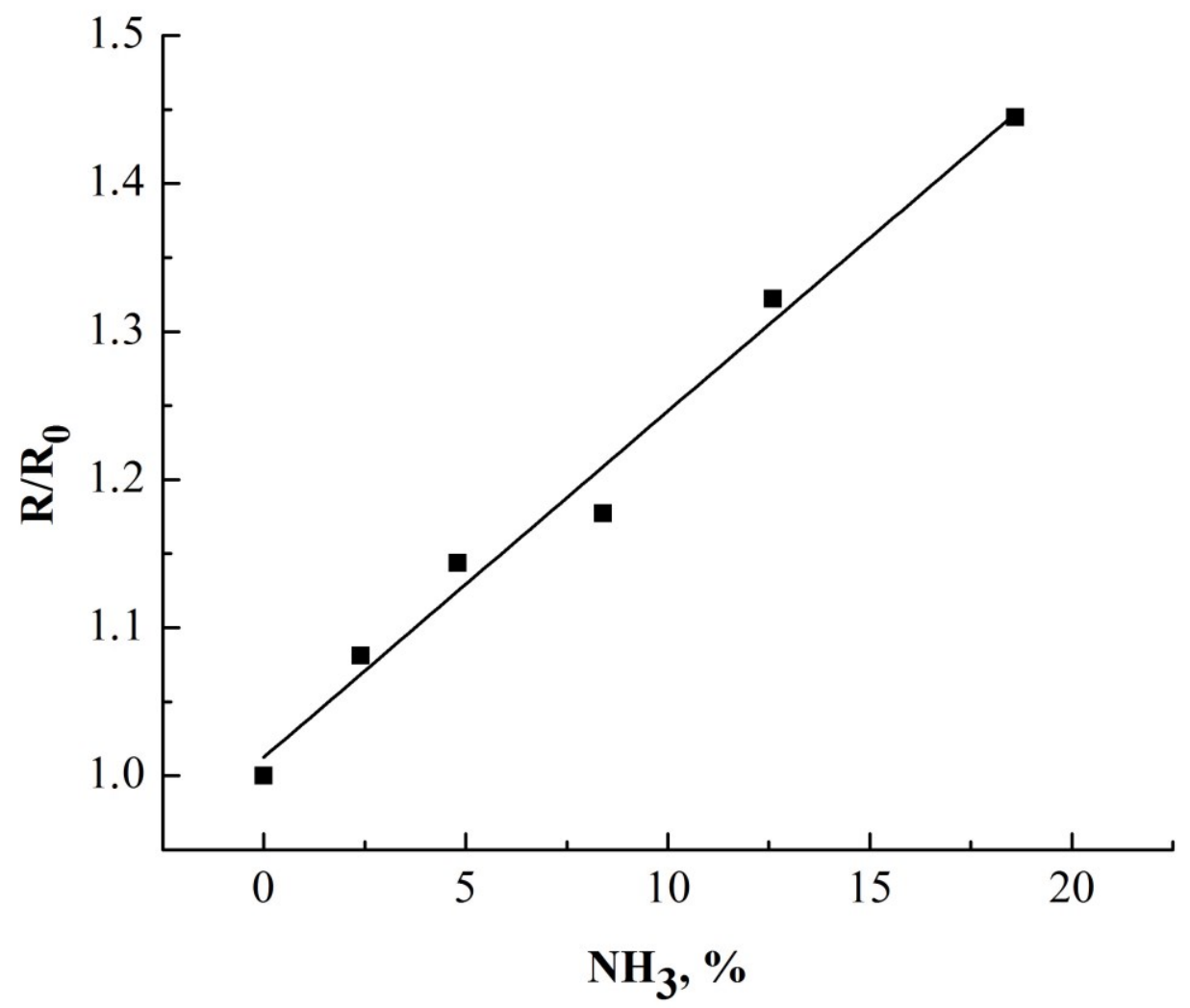

Fig. 6. Resistance response dependence on ammonia concentration measured in region A in Fig.5. 


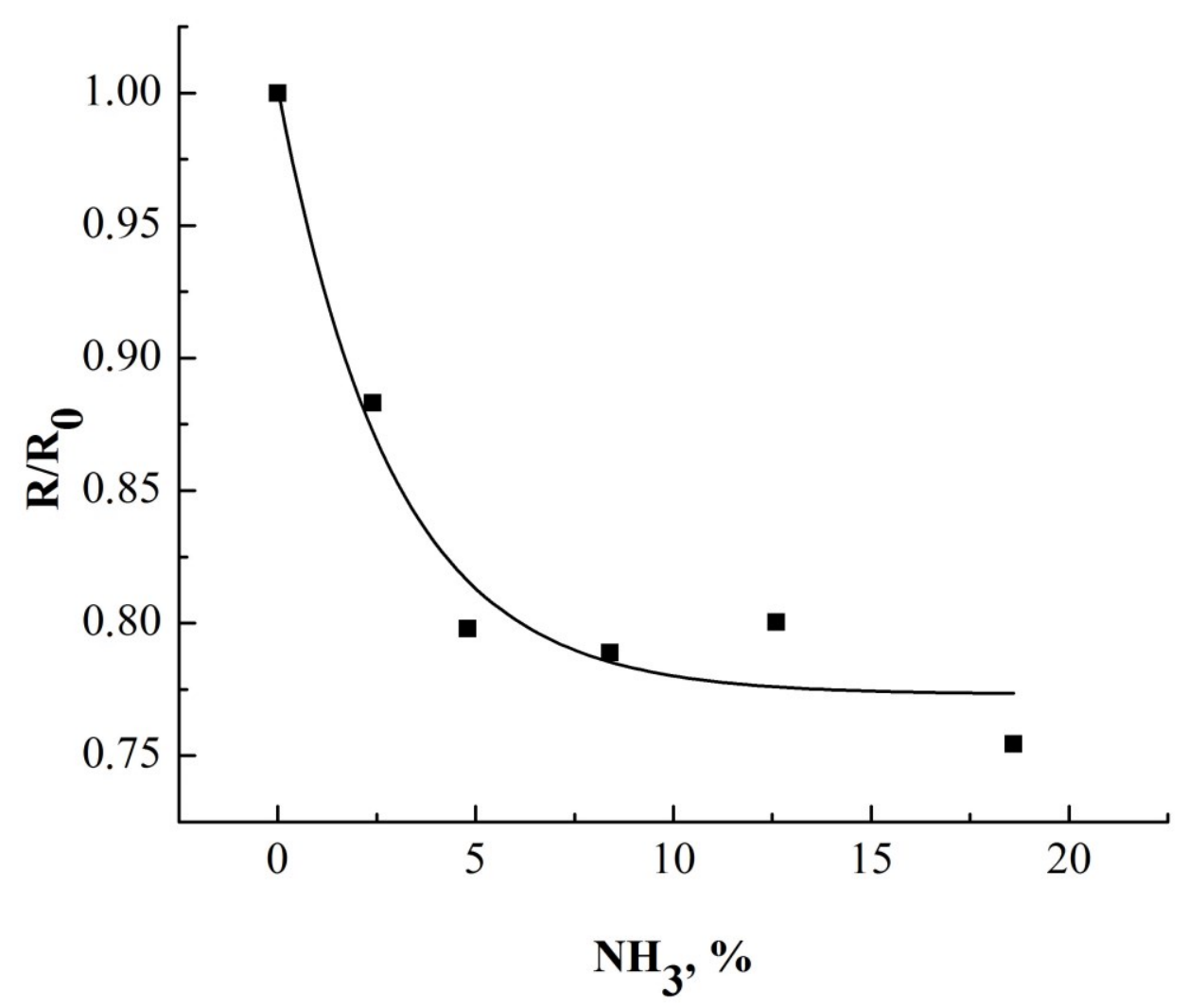

Fig. 7. Resistance response dependence on ammonia concentration measured in region B in Fig.5.

\section{References}

[1] N. Yamazoe, N. Miura, Environmental gas sensing, Sens. Actuators B 20 (1994) 95-102.

[2] U. Weimar, W. Göpel, Chemical imaging: II. Trends in practical multiparameter sensor systems, Sens. Actuators B 52 (1998) 143-161.

[3] D.E. Williams. Semiconducting oxides as gas-sensitive resistors, Sens. Actuators B 57 (1999) $1-16$.

[4] A. Galdikas, A. Mironas, V. Strazdienè, A. Šetkus, I. Ancutienè, V. Janickis, Room temperature-functioning ammonia sensor based on solid-state $\mathrm{Cu}_{\mathrm{x}} \mathrm{S}$ films, Sens. Actuators B 67 (2000) 76-83.

[5] A. Šetkus, A. Galdikas, A. Mironas, V. Strazdienė, I. Šimkienė, I. Ancutienè, V. Janickas, S. Kačiulis, G. Mattogno, G.M. Ingo, The room temperature ammonia sensors based on improved $\mathrm{Cu}_{\mathrm{x}} \mathrm{S}$-microporous-Si structure, Sens. Actuators B 78 (2001) 208-215.

[6] D. R. Ulrich, Prospects for sol-gel processes, J. Non-Cryst. Solids 121 (1990) 465-479.

[7] J. Livage, Synthesis of polyoxovanadates via "chimie douce", Coord. Chem. Rev. 178-180 (1998) 999-1018.

[8] V. L. Volkov, G. S. Zakharova, V. M. Bondarenka, Simple and modificated xerogels of polyvanadates, Ural Branch of Russian Acad. of Sci., Yekaterinburg, 2001 (in Russian).

[9] V. Bondarenka, S. Grebinskij, S. Mickevicius, V. Volkov, G. Zakharova, Influence of humidity on electrical properties of polyvanadium molybdenum acid, Lithuanian J. Phys. 33 (1993) $222-226$.

[10] V. Bondarenka, S. Grebinskij, S. Mickevičius, V. Volkov, G. Zakharova, Thin films of polyvanadium-molybdenum acid as starting materials for humidity sensors, Sensors and Actuators B 28 (1995) 227-231. 
[11] V. L. Volkov, G. S. Zakharova, L. V. Kristallov, M. V. Kuznetsov, G. Dai and M. Tong, Synthesis, structure, and properties of ammonium polyvanadomolybdate xerogels, Inorg. Mater. 37 (2001) 408-412.

[12] D. A. Shirley, High-resolution X-ray photoemission spectrum of the valence bands of gold, Phys. Rev. B 5 (1972) 4709-4714.

[13] C. D. Wagner, J. F. Moulder, L. E. Davis, W. M. Riggs, Handbook of X-ray PhotoelectronSpectroscopy, Perkin.Elmer Corporation, Physical Electronics Division, 1995.

[14] B. F. Dzhurinskii, D. Gati, N. P. Sergushin, V. I. Nefedov, Ya. V. Salyn, Simple and coordination compounds. An X-ray photoelectron spectroscopic study of certain oxides, Zh. Neorg. Khim. (Russ. J. Inorg. Chem.) 20 (1975) 2307-2314 (in Russian).

[15] G. Hopfengärtner, D. Borgmann, I. Rademcher, G. Wedler, E. Hums, G.W. Spitznagel, XPS studies of oxidic model catalysts: Internal standards and oxidation numbers, J. Electron Spectrosc. Related Phenomena 63 (1993) 91-116.

[16] T. L. Barr, An ESCA study of termination of the passivation of elemental metals, J. Phys. Chem. 82 (1978) 1801-1810.

[17] C. O. A. Olsson, S.E. Hornstrom, An AES and XPS study of the high alloy austenic stainless steel 254 SMO tested in a ferric chloride solution, Corrosion Sci. 36 (1994) 141-151.

[18] G. D. Khattak, M. A. Salim, A. S. Al-Harthi, D. J. Thompson, L. E. Wenger, Structure of molybdenum-phosphate glasses by X-ray photoelectron spectroscopy (XPS), J. Non-Cryst. Solids 212 (1997) 180-181.

[19] C. R. Clayton, K. G. Martin, Evidence of anodic segregation of nitrogen in high nitrogen stainless steels and its influence on passivity, in: eds. A. Hendry and J. Foche, Proceedings of International Conference on High Nitrogen Steel HNS 88, Lille, London (1989) 256-260.

[20] V. Bondarenka, S. Kaciulis, A. Plesanovas, V. Volkov, G. Zacharova, Photoelectron spectroscopy of the poly-vanadium transition metal acids, Appl. Surf. Sci.78 (1994) 107-112.

( Received 21 April 2015; accepted 02 May 2015 ) 